\title{
The Kornati fire accident - eruptive fire in relatively low fuel load herbaceous fuel conditions
}

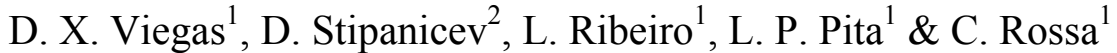 \\ ${ }^{I}$ Department of Mechanical Engineering, University of Coimbra, \\ Coimbra, Portugal \\ ${ }^{2}$ Faculty of Electrical Engineering, \\ Mechanical Engineering and Naval Architecture, University of Split, \\ Split, Croatia
}

\begin{abstract}
The biggest fire fighting accident in the history of Croatia happened on August 30,2007 . The routine fire fighting operation ended with 12 dead and 1 badly injured fire-fighter. That was the biggest human loss in the history of fire fighting in Croatia. In order to understand the Kornati accident a research team was formed and independent scientific investigation performed. The accident was analyzed from meteorological, vegetation, thermodynamics and aerodynamic points of view, and several simulation models of fire propagation were used. This paper describes in detail one possible explanation connected with eruptive fire behavior. Eruptive fire behavior has been reported in many fire accidents in the past causing a lot of causalities. Based on the real Kornati accident data, the eruptive fire model was conceived and appropriate results derived. The paper describes them in detail. Our aim in studying this and other accidents is not to find who is guilty or to blame anyone but rather to find what happened and to extract lessons, to avoid future accidents.
\end{abstract}

Keywords: forest fire accident, eruptive fire.

\section{Introduction}

The accident of Kornat Island was very unfortunate for the loss of 12 lives. It is known that the fire started at Vrulja Bay between 11:00 and 11:30 on August 
30th 2007 and the accident occurred at Sipnate canyon at between 15.15 and $15: 20$. The distance between these two points is around $6.6 \mathrm{~km}$, so the average Rate of Spread (ROS) was therefore of the order of $1.97 \mathrm{~km} / \mathrm{h}(54 \mathrm{~cm} / \mathrm{s})$. The place of accidence was Sipnate canyon, a relatively small canyon long about $500 \mathrm{~m}$, closed from three sides (east, north and west) and opened only from the south.

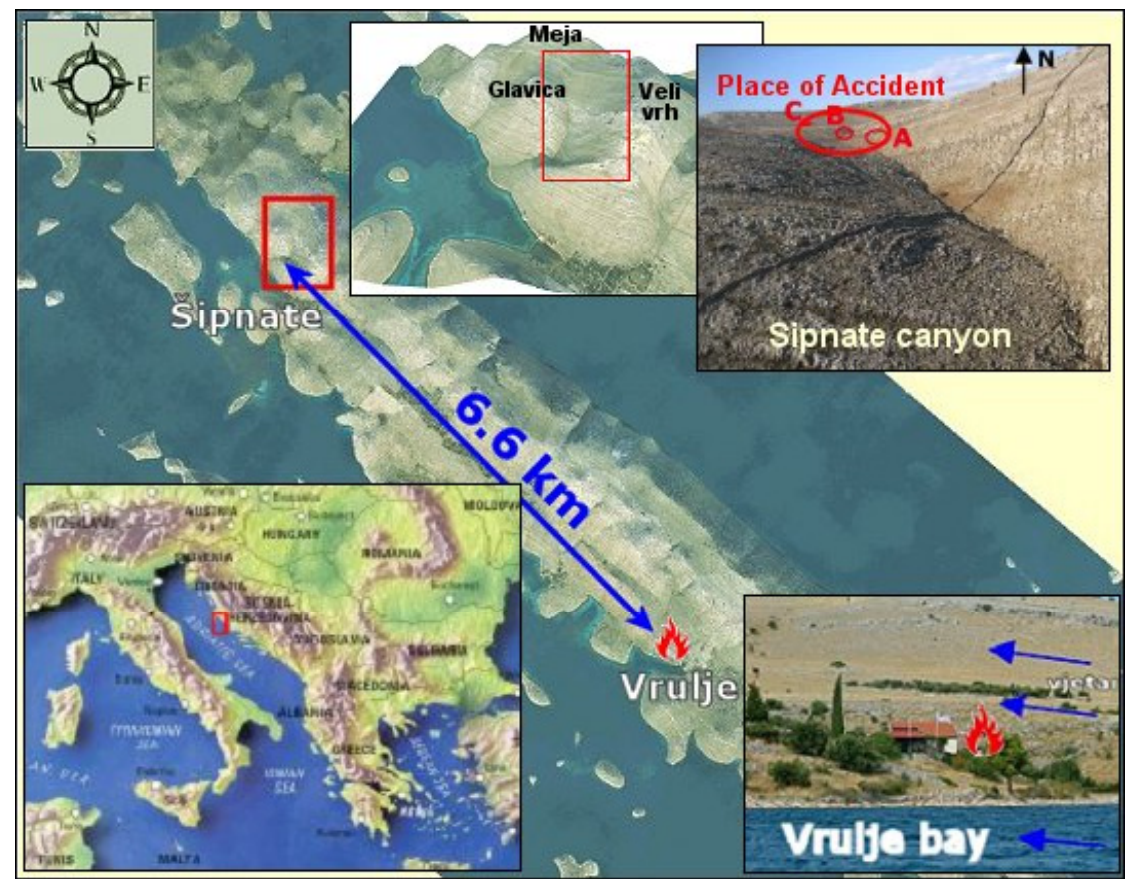

Figure 1: Ignition point and the place of accident - the Sipnate canyon.

According to reconstruction [1-3], the helicopter with fire-fighters has landed at the north side of Sipnate canyon on the top of Meja hill at 14:58. After landing the fire-fighters were on their way to water reservoir left by the same helicopter previously on the south slope of hill Veli vrh. Fire front was approaching from the south east, following the main island axis, but the propagation on the north side of island was faster, so the fire-fighters saw the fire front on the east side of canyon, on the north-east and east slopes of Veli vrh first. They decided to go back, so they turned in a west direction, exactly toward the canyon axis.

The last contacts with fire-fighters asking for help were at 15:25, so we suppose that the accident happened between 15:15 and 15:25. In the rest of this paper we will describe experiments and simulations performed to prove the hypothesis that the eruptive fire effect was developed in the Sipnate canyon on August 30th and maybe responsible for the accident. Our aim in studying this accident is not to find who is guilty or to blame anyone but rather to find what happened and to extract lessons, to avoid future accidents. We hope that the fire- 
fighting service in Croatia will be improved and that in the future it will be possible to predict such situations.

\section{The input data - canyon geometry, vegetation, meteorology and important facts}

The Kornat island is a rocky island with no pathways. The canyon has rather complex topography $[1,2]$. It is about $500 \mathrm{~m}$ long having two sections. The first one is in direction from SW to NE, and the second one $350 \mathrm{~m}$ long in direction from $\mathrm{S}$ to $\mathrm{N}$. The canyon is closed from three sides, on the east side by hill Veli vrh $(212 \mathrm{~m})$, on the north side by hill Meja $(150 \mathrm{~m})$ and on the west side by hill Glavica $(135 \mathrm{~m})$. It is opened only on its south part. The canyon main axis in the second part is directed from $\mathrm{S}$ to $\mathrm{N}$, with $16 \%\left(9^{\circ}\right)$ average slope. Slopes on the left and right side are variable with maximal value on the left side (Glavica) 29\% $\left(16^{\circ}\right)$ and on the right side (Veli vrh) $45 \%\left(24^{\circ}\right)$. Total area of the burned canyon bottom was $99887 \mathrm{~m}^{2}$ (cca. 10 ha). Fig 2 shows the most important parameters of Sipnate canyon configuration.

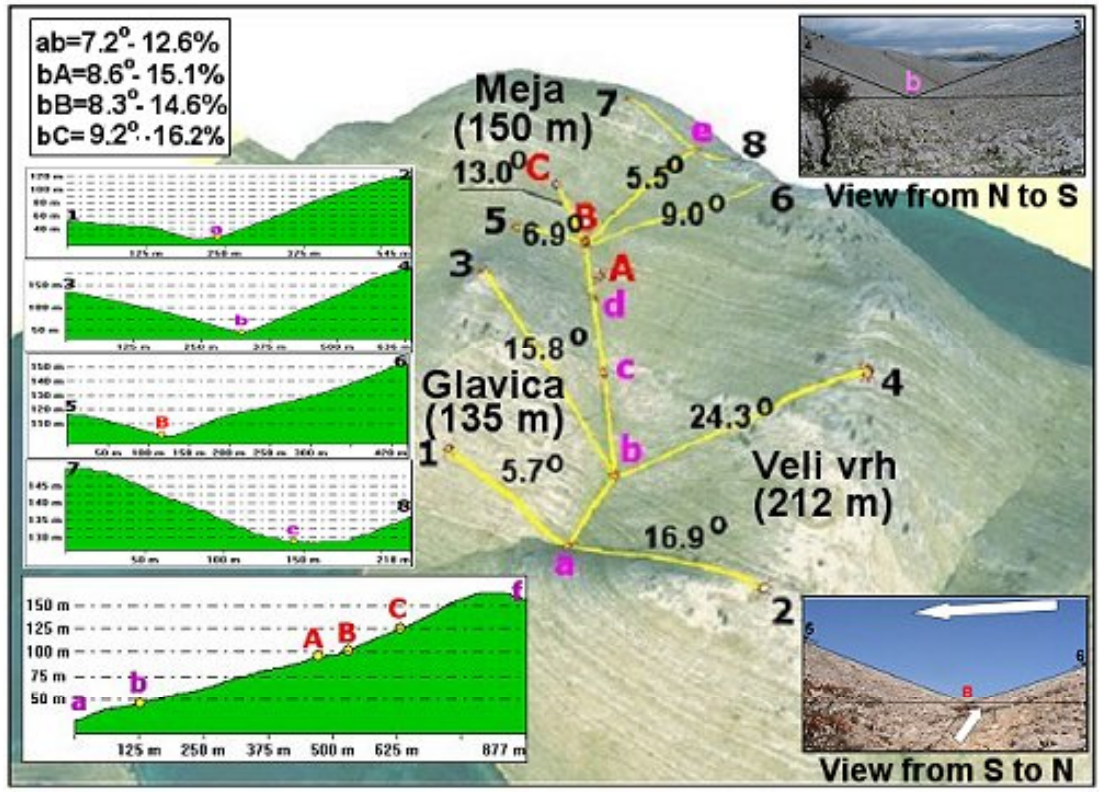

Figure 2: $\quad$ The most important parameters of Sipnate canyon.

On the whole island there is low and rare vegetation, mostly grass, with 35$45 \%$ of woody vegetation and total cover between $45-55 \%$. Only several small isolated trees and bushes were recorded. Vegetation was sampled and analysed by researchers from Faculty of Forestry University of Zagreb [1, 2]. The fuel load ranged from $0.561-0.837 \mathrm{~kg} / \mathrm{m}^{2}$ and the average vegetation heat content 
was estimated to be $18000 \mathrm{~kJ} / \mathrm{kg}$. Vegetation was extremely flammable with ignition delay less than $2 \mathrm{~s}$, and the average experimentally measured burning time of grass vegetation was $12 \mathrm{~s}$. The Fine Fuel Moisture Content (FFMC) of grass vegetation ranged from 12 to $14 \%$.

On the day of accident the strong S-E wind (this wind has the local designation of jugo) was blowing, exceeding $10 \mathrm{~m} / \mathrm{s}(36 \mathrm{~km} / \mathrm{h})$ at $10 \mathrm{~m}$ height, according to official meteorological reports. In Sipnate canyon the mid flame wind direction was parallel with the main canyon axis and mid flame speed between $1.8-4 \mathrm{~m} / \mathrm{s}(6.4-14.4 \mathrm{~km} / \mathrm{h})$.

Few other facts are also important $[1,2]$. Three trees located on the line of fire spread were not burned, except leafs in their bottom parts, varying from $0.5 \mathrm{~m}$ on the south side of canyon to $3.0 \mathrm{~m}$ on the north side. Interesting is the fact that leafs on the top of the trees were not burned, only dehydrated and 'frozen' showing the direction of the hot air flow exactly from the south to the north.

The upper half part of the hill Glavica on the west side was unburned. Vegetation samples were collected on this slope. Fig 3 also shows interesting evidence that proves the existence of strong wind from south to north. It shows the stone $2 \mathrm{~m}$ behind the place where one fire-fighter was found with particles of melted polyester. The fire-fighter cloth had a great percentage of polyester. This proves that the wind speed generated by the fire was very strong, and that the temperature was very high.

At the end let us mention that the only one surviving fire-fighter said that the heat and the fire came from the bottom of the canyon (south part) creating a train like noise.

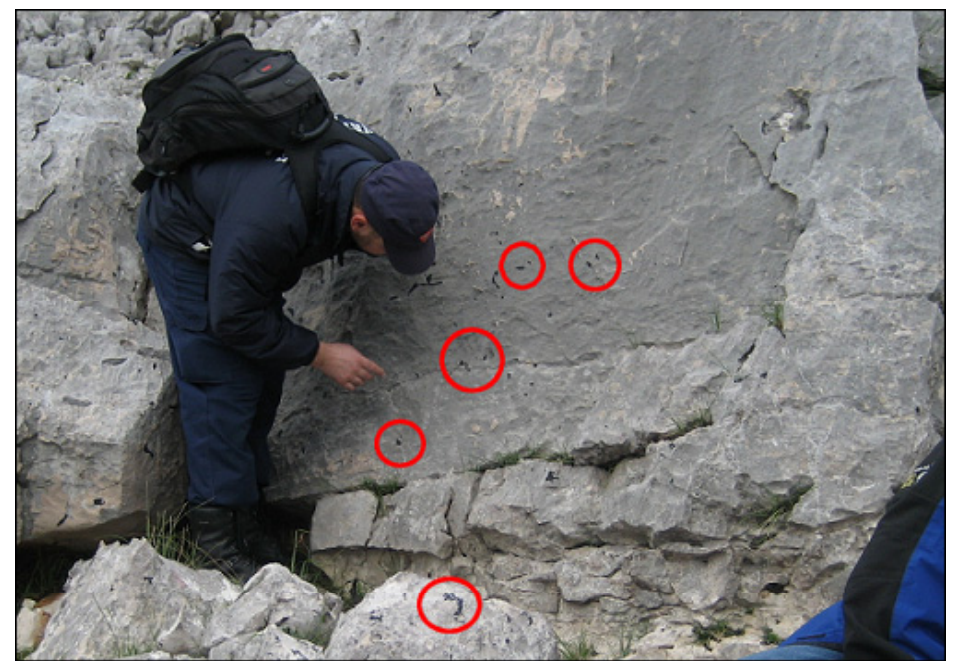

Figure 3: On the stones behind the place where one fire-fighter was found the melted particles of the fire-fighter dolmen were found proving that the wind generated by fire was very strong coming from the south. 


\section{General simulation of the fire}

Although this paper is dedicated mostly to the analysis of the fire spread related to the accident we developed simulations of the fire since its origin at Vrulia bay till its end. The objective of this simulation was to assess the type of fuel model that was considered in the study.

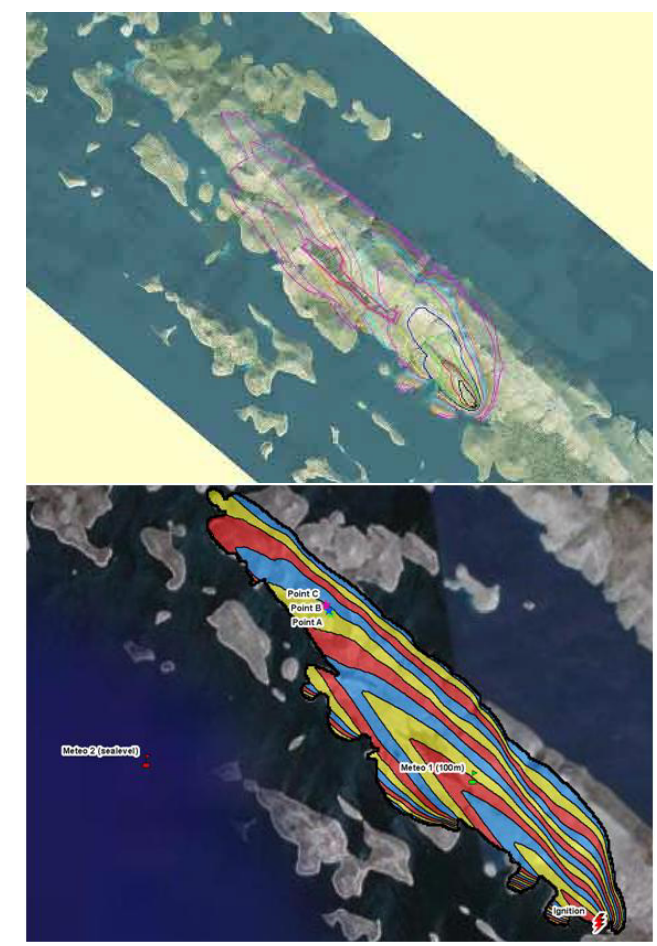

Figure 4: Prediction of the general fire spread on Kornat Island using iForestFire simulator (a) and Firestation (b). The contours correspond to the perimeter of the fire at 30 minute intervals.

Simulations were performed using two fire simulators: iForestFire simulator based on Rothermel equations and cellular automata [4], and Firestation [5]. The simulation outputs produced using both simulators are shown in figure 4 . The parameters that were used in these simulations, which correspond to the Albini Anderson GR1 category [6, 7], are presented in Table 1.

According to these simulations the time elapsed since the fire start till it reached Sipnate bay was of the order of 4 hours which compares well with the reported time of the accident. It is important to emphasize that simulations show faster propagation of the fire front on the north side of Kornat island. Witnesses mention this fact too, and it was used in reconstruction of the fire-fighters path mentioned in Sections 1 and 4. 
Table 1: $\quad$ Parameters used in fire propagation simulation from the ignition point.

\begin{tabular}{|c|c|c|c|c|c|c|c|c|}
\hline \multirow{2}{*}{$\begin{array}{c}\text { Fuel } \\
\text { Model }\end{array}$} & \multicolumn{4}{|c|}{ Fuel Load $\left(\mathrm{kg} / \mathrm{m}^{2}\right)$} & \multirow{2}{*}{$\sigma$} & Depth & Heat & \multirow{2}{*}{$\mathrm{m}_{\mathrm{x}}$} \\
\cline { 2 - 8 } & $1 \mathrm{hr}$. & $\begin{array}{c}10 \\
\mathrm{hr}\end{array}$ & $\begin{array}{c}100 \\
\mathrm{hr} .\end{array}$ & $<6 \mathrm{~mm}$ & $\mathrm{~cm}^{-1}$ & $\mathrm{~m}$ & $\mathrm{~kJ} / \mathrm{kg}$ & $\%$ \\
\hline GR1 & 0.025 & 0 & 0 & 0.074 & 72 & 0.122 & 1862 & 15 \\
\hline
\end{tabular}

\section{Description of the accident}

From the research that was carried out by the authors and by other persons it was possible to reconstruct at least partially the events that preceded the accident. We shall describe them very briefly here.

The group of 13 fire fighters was carried out in a MIL8 helicopter that transported before a collapsible container full of water to support fire fighting. The helicopter landed near point 4 in fig. 2 where it left the water container and went to pick up the firelighters near Sipnate bay. As there was no space to land again near the water container the helicopter landed further up in the canyon near point 7 in fig. 2 . The fire fighters started to walk on the very difficult terrain of the island in the direction of the water container to start attacking the fire. They carried some motor pumps, back-pack hand pumps, fuel containers and other tools but they did not have water. On their way they found that the fire line was along the crest of the ridge so they turned to go around it. In the process of surrounding the fire line the group started to descend along the Eastern slope of Sipnate canyon and to actually place them near point $A$ at the water line of this canyon.

Certainly unknown to them the southernmost edge of the fire line had probably entered the base of the canyon much below their position. Given the configuration of the canyon and the curvature of its water line from the position A the group could not see the bottom of the canyon. Therefore they must have realized that the fire was below them quite late to have a chance to escape collectively. Most of the equipment was dropped by the fire fighters near point A. It was also near this point that the majority of the victims were found. The only survivor was a fire fighter that remained slightly behind the group and escaped from the very intense and quick fire updraft along the canyon.

A small group of fire fighters managed to reach point $B$ but were found dead there. Remarkably a fire fighter was able to run until point $\mathrm{C}$ in spite of the extremely difficult terrain conditions but he was overwhelmed by the hot gases produced by the fire.

\section{Laboratory simulation of fire}

A laboratory simulation of the fire evolution in Sipnate canyon was performed by the authors at the Forest Fire Laboratory of the University of Coimbra at its large canyon table DE4. Due to lack of space only few details of the 
experimental conditions are given here. The Table has two faces that were set at the inclination angles given in fig. 5 in order to represent the basic shape of the lower part of the canyon. The fuel that was used in the tests was straw that replicated well the combustibility properties of the herbaceous fuel that existed largely in the area. An ignition line was set at the position shown in the same figure.

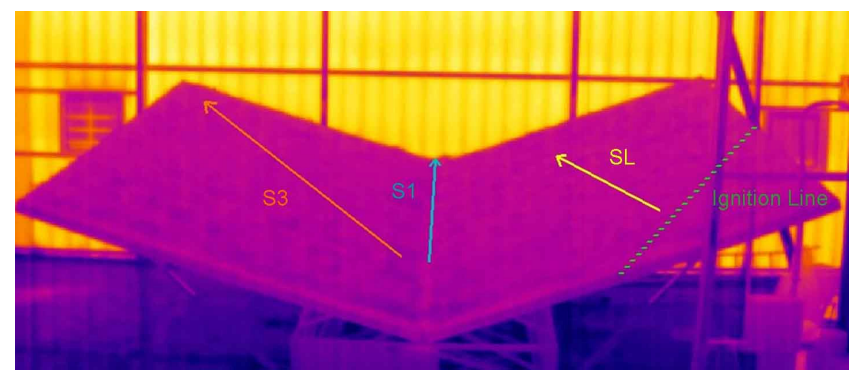

Figure 5: Schematic view of the canyon table of the forest fire laboratory of the University of Coimbra indicating the position of the ignition line and the three directions S1, S2, and S3 along which the fire spread was analysed.

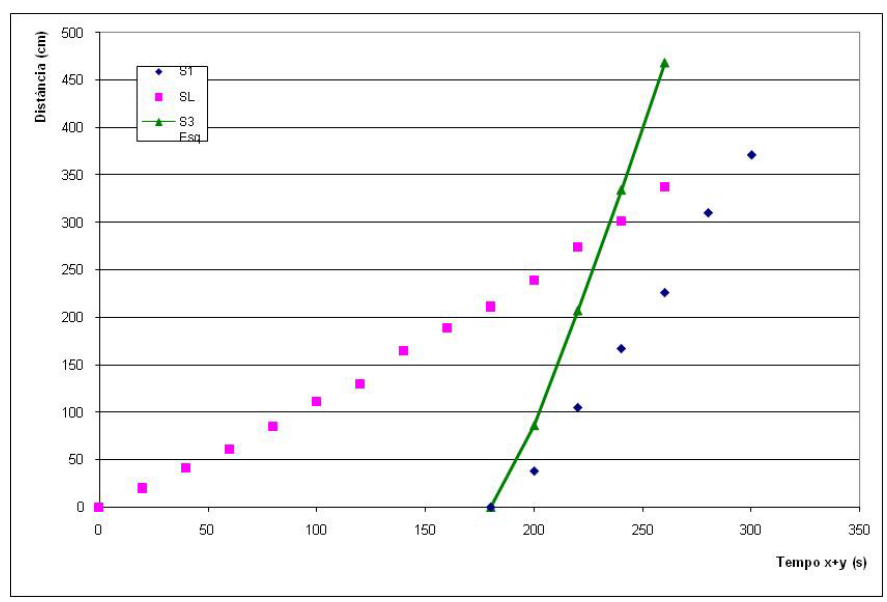

Figure 6: Distance travelled by the fire along the three main directions indicated in figure 5 .

Video and infra-red cameras were used to register the experiments. Several experiments were carried out with slight differences in the pattern of ignition. The evolution of the fire front along the three main directions S1, S2 and S3 was analyzed from the IR images and the results are shown in figure 6 . As can be seen in this figure the linear fire front propagated relatively slowly down slope towards the water line (direction S3) but when it reached this line and the bottom 
of the eastern slope of the canyon it spread very rapidly along it (line S2) and along the water line (S1). Given the differences in scale and configuration we do not claim that these experiments replicate with great precision the fire spread conditions before and during the accident but they do show some very important qualitative features of the fire in this process.

We can see that the spread along S2 exhibits an acceleration that is characteristic of eruptive fire behavior. In our opinion this was most likely to have occurred in Sipnate canyon before the accident. One other point that we can see in that figure is that the fire spread along the water line (line S1) was also very quick and it happened almost at the same time as the other eruption. This is consistent with the fact that the group of fire fighters were caught near the water line and on the West side of it.

We remark that in this test no wind was used over the test area. Comparing with the actual situation of the accident we know that the presence of a relatively strong wind aligned with Sipnate canyon would make these conditions even worse.

\section{Application of the eruptive fire mathematical model}

Given the evidence of the very likely existence of an eruptive propagation of the fire in Sipnate canyon we shall apply the mathematical model [8] to predict the rate of spread of the head fire in this case. In spite of the simplicity of the mathematical model it is necessary to know the adequate parameters and initial conditions in order to apply it. As the properties of the fuel bed that existed in Kornat Island are not yet well known we can only apply the parameters that were measured for similar fuels assuming that they are analogous to the conditions in Sipnate canyon. We shall use the following set of parameters in order to apply the mathematical model to estimate the advance of the head fire along the water line of the canyon and along the left (East) slope of the canyon.

Table 2: $\quad$ Parameters used in eruptive fire mathematical model.

\begin{tabular}{|c|c|c|c|c|c|c|}
\hline $\mathrm{R}_{\mathrm{o}}(\mathrm{cm} / \mathrm{s})$ & $\mathrm{R}_{\mathrm{i}}$ & $\mathrm{t}_{\mathrm{o}}(\mathrm{s})$ & $\mathrm{b}_{1}$ & $\mathrm{~b}_{2}$ & $\mathrm{a}_{1}{ }_{1}$ & $\mathrm{a}_{2}{ }_{2}$ \\
\hline 0.61 & 1.5 & 50 & 1.8 & 1.0 & 0.2 & 0.2 \\
\hline
\end{tabular}

Using the above mentioned values the differential equation of the rate of spread was integrated twice to determine the distance of advance of the head fire since its arrival at the water line of the canyon (at point $a$ of figure 2) and the result is shown in figure 7 . The relevant points of the trajectory of the head fire along the water line of the canyon are indicated on the curve.

If the prediction that is indicated in this figure is correct we can see that since the fire entered the base of the canyon it may have taken some minutes to reach point $b$, but from this point onwards it must have taken less than two minutes to reach the main group at positions $\mathrm{A}$ and $\mathrm{B}$. In less than three minutes it must have reached position $\mathrm{C}$. These time intervals are consistent with the distances and displacement times that would be required to travel from $\mathrm{A}$ to $\mathrm{b}$ and to $\mathrm{C}$. If 
we assume a displacement velocity of $2 \mathrm{~m} / \mathrm{s}$ for the escaping fire fighters they would require between one and three minutes to reach from $\mathrm{A}$ to $\mathrm{B}$ or to $\mathrm{C}$ respectively, taking into account the difficulties of the terrain.

We remark that the presence of flames at the bottom of the canyon could only be perceived when they reached point $b$, although we can assume that the presence of smoke could have been perceived a bit earlier and might have triggered the alarm one or two minutes before. Even so it was probably too late for the group to reach a safe zone.

In this simulation we also did not consider the effect of the wind on the fire eruption. Based on our previous observations we assume that the presence of wind might anticipate the moment of eruption but would not otherwise change the sequence of events. The eruption would have occurred with the support of the wind giving even less time for the group to escape from the fire.

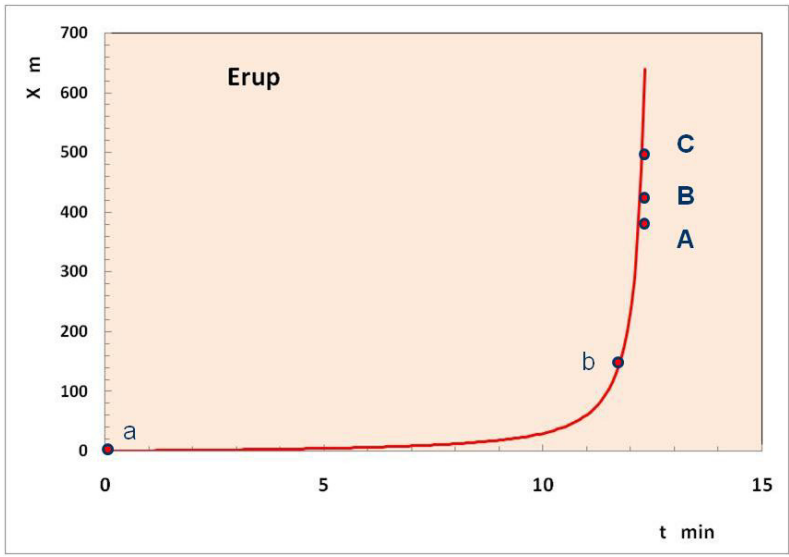

Figure 7: $\quad$ Predicted distance of advance of the fire along the water line of Sipnate canyon with time since its entrance at the base of the canyon at point $a$.

\section{Similar cases}

This accident follows the pattern of several other cases that have occurred in other parts of the World, some of which have been studied by the authors. One of the common aspects of all accidents with multiple fatalities involving well trained and experienced fire fighters is the presence of a sudden acceleration of the fire front in a slope or in a canyon. That is why we say [9] that eruptive fire behavior is a common factor in most of these accidents.

Below we give a list of some cases that are reported and that can be analyzed in comparison to the Kornati accident to confirm our assertion. Some of these cases are being investigated by the authors and the conclusions are not published yet. 
Table 3: $\quad$ Cases of investigated eruptive fire.

\begin{tabular}{|c|l|c|c|c|c|}
\hline & \multicolumn{1}{|c|}{ Case } & Date & Victims & Country & Ref. \\
\hline 1 & Mann Gulch & $05-08-1949$ & 13 & USA & {$[10]$} \\
\hline 2 & Sintra & $07-09-1966$ & 25 & Portugal & {$\left[{ }^{*}\right]$} \\
\hline 3 & Curragia & $06-08-1973$ & 9 & Italy & {$\left[{ }^{*}\right]$} \\
\hline 4 & La Gomera & $13-09-1984$ & 20 & Spain & {$\left[{ }^{*}\right]$} \\
\hline 5 & South Canyon & $06-07-1994$ & & USA & {$[11]$} \\
\hline 6 & Palasca & $17-09-2000$ & 2 & France & {$\left[{ }^{*}\right]$} \\
\hline 7 & Freixo de Espada a Cinta & $07-08-2003$ & 2 & Portugal & {$[8]$} \\
\hline 8 & Mortagua & $28-02-2005$ & 4 & Portugal & {$\left[{ }^{*}\right]$} \\
\hline 9 & Guadalajara & $17-07-2005$ & 11 & Spain & {$\left[{ }^{*}\right]$} \\
\hline 10 & Famalicão da Serra & $09-07-2006$ & 6 & Portugal & {$\left[{ }^{*}\right]$} \\
\hline
\end{tabular}

[*] Not reported, under investigation.

\section{Conclusions}

The fire that occurred in Kornat Island on the $30^{\text {th }}$ of August of 2007 and the accident that caused the loss of twelve Croatian fire fighters were analyzed. It was found that the fuel model GR1 seems to represent well the combustibility properties of the vegetation that covered most of the island. From the analysis of the accident the hypothesis of a fire eruption from the base of Sipnate canyon to its top is proposed as the best explanation for the sequence of events and for the fact that the group of fire fighters did not have time to reach a safety zone and escape the fire. Preliminary laboratory simulations in a canyon table support this hypothesis. The application of the mathematical model to predict the advance of an eruptive fire front provides results that are consistent with the other findings related to this accident. The analogies between the Kornati accident and other similar cases with multiple fatalities that are known to the authors provide further support to the explanation that is proposed in the present study.

\section{References}

[1] Interdisciplinary working group, The Kornati Accident Report, Split, Zagreb, Croatia, 304 pages, Feb. 2008 (in Croatian)

[2] Stipanicev, D., Spanjol, Z., Vucetic, M., Vucetic, V., Rosavec, R., Bodrozic, Lj., The Kornati Fire Accident Facts and Figures Configuration, Vegetation and Meteorology, Forest Fires 2008, Toledo (this conference)

[3] Klarin, B., Ninic, N., Stipanicev, D., Nizetic, S., Krstinic, D., The Kornati Fire Accident - Aerodynamics and Thermodynamics Aspects, Forest Fires 2008, Toledo (this conference)

[4] Stipaničev, D. Hrastnik, B., Vujčić, R., Holistic Approach to Forest Fire Protection in Split and Dalmatia County of Croatia, Wildfire 2007 Int. Conference, Sevilla, Spain, May 2007. 
[5] Lopes, A.M.G., Cruz, M.G and Viegas, D.X. (1998) - "FireStation - An Integrated System for the Simulation of Wind Flow and Fire Spread over Complex Terrain", II International Conference on Fire and Forest Meteorology, Vol. I, pp. 741-754, Luso - Coimbra

[6] Anderson, H.E. 1982. Aids to determining fuel models for estimating fire behaviour. USDA For. Serv. Res. Pap. INT-122, Intermountain For. and Range Exp. Stn., Ogden Utah, 22 p.

[7] Cruz, M.G. Guia fotográfico para identificação de combustíveis florestais Região Centro de Portugal. Centro de Estudos sobre Incêndios Florestais ADAI, Coimbra. 38p.

[8] Viegas D.X, 2005. A Mathematical Model for Forest Fires Blow-up. Combustion Science and Technology. 177:1-25.

[9] Viegas D.X. 2006. Analysis of Eruptive Fire Behaviour, V Conference on Forest Fire Research, Figueira da Foz, Portugal, Nov. 2006, 13 p.

[10] Rothermel, Richard C. 1993. Mann Gulch fire: a race that couldn't be won. Gen. Tech. Rep. INT-299. Ogden, UT: U.S. Department of Agriculture, Forest Service, Intermountain Research Station. $10 \mathrm{p}$.

[11] Butler, Bret W.; Bartlette, Roberta A.; Bradshaw, Larry S.; Cohen, Jack D.; Andrews, Patricia L.; Putnam, Ted; Mangan, Richard J. 1998. Fire behavior associated with the 1994 South Canyon Fire on Storm King Mountain, Colorado. Res. Pap. RMRS-RP-9. Ogden, UT: U.S. Department of Agriculture, Forest Service, Rocky Mountain Research Station. 82 p.

[12] Scott, Joe H.; Burgan, Robert E. 2005. Standard fire behavior fuel models: a comprehensive set for use with Rothermel's surface fire spread model. Gen. Tech. Rep. RMRS-GTR-153. Fort Collins, CO: U.S. Department of Agriculture, Forest Service, Rocky Mountain Research Station. 72 p. 